Z. Klin. Chem. Klin. Biochem.

11. Jg. 1973, S. $335-338$

\title{
Microdetermination of Hemoglobin Iron ${ }^{1,2)}$
}

\author{
By A. Manasterski1 ${ }^{1}$, R. Watkins ${ }^{2}$, E. S. Baginski ${ }^{3}$ and B. Za K ${ }^{1,2,4}$ \\ From the Departments of Biochemistry ${ }^{1}$ and Pathology ${ }^{4}$, Wayne State University School of Medicine, and the Departments \\ of Pathology, Detroit General Hospital' ${ }^{2}$, Detroit, Michigan and St. Joseph Mercy Hospital ${ }^{3}$, Pontiac, Michigan
}

(Eingegangen am 6. November 1972/29. Januar 1973)

A procedure for the determination of blood hemoglobin iron is described for two ligands of similar sensitivity where each is equally suitable for the described purpose. The systems are relatively rapid, sensitive and trouble free when applied to standardization in hemoglobinometry.

Es werden Methoden zur Bestimmung von Hämoglobineisen im Blut beschrieben, die zwei Liganden mit gleicher Sensitivität verwenden. Beide können mit gleicher Aussagekraft verwandt werden. Die Methoden sind schnell durchführbar, empfindlich und komplikationslos, wenn sie zur Standardisierung bei der Hämoglobinometrie verwandt werden.

Many clinical laboratories use commercial prediluted solutions as standards to calibrate their hemoglobin determinations. However, it seems more desirable to have a standard hemoglobin solution easily calibrated according to its iron content which can be used in the same fashion as the analyzed blood. The advantages are obvious and the approach can be used for the determination of hemoglobin itself (1) or for standardization of the system (2-4). Several reagents have been described for the purpose of standardization $(5-10)$, but all of them are inferior in terms of sensitivity to 3-(2-pyridyl)-5,6-bis(4-phenylsulfonic acid)-1,2,4 triazine called ferrozine $(11,12)$ and 2,6-bis (4-phenyl-2-pyridyl)4-phenyl pyridine sulfonate called terosite sulfonate. The former has a reported molar absorptivity of $27,900 \mathrm{~cm}^{2} / \mathrm{mol} \mathrm{(13)} \mathrm{while} \mathrm{the} \mathrm{latter} \mathrm{has} \mathrm{one} \mathrm{of}$ $30,200 \mathrm{~cm}^{2} / \mathrm{mol}$ (14).

In the course of hemoglobin iron determination, wet ashing (7) or dry ashing techniques (14) may be employed to liberate iron from hemoglobin and this approach has been suggested recently (15) along with a rather insensitive color reagent, thioglycolic acid, for the iron determination. Other methods for liberating iron from hemoglobin have included the use of persulfate in the cold (16) or chloric acid plus heat (8). The substitution of clorox (17) for chloric acid eliminates the need to heat the sample even though there is no real time saving in the determination. However, the ability to solubilize the hemoglobin solution to render it clear without prior deproteinization is advantageous.

The purpose of the present study is to describe a simple method for the determination of hemoglobin either for the purpose of standardization in hemoglobinometry or for the determination of hemoglobin in blood by means of its iron content. Iron is liberated by clorox $(5,17)$ prior to reaction with either of the two most sensitive iron reagents known (11, 13, 14). Easily available polyoxethylene lauryl ether, called Brij-35, is used as the protein solubilizer and solution clarifier so that deproteinization is unnecessary.

\section{Materials and Methods}

Reagents

1. Clorox solution (The Clorox Company, Oakland, California). Commercially available clorox solution has worked well in this procedure undiluted. It is considered to be pure and made up at $\mathrm{pH} 11.4$ from $5.4 \% \mathrm{NaOCl}, 4.2 \% \mathrm{NaCl}$ and $0.2 \% \mathrm{Na}_{2} \mathrm{CO}_{3}$ $(5,17)$.

2. Brij-35 solution (Technicon Corporation, Chauncey, New York). Dilute the $25 \%$ solution of polyoxyethylene lauryl ether, Brij-35, 1:5 with iron-free distilled $\mathrm{H}_{2} \mathrm{O}$. This is a detergent commonly used in on stream automation.

3. Ferrozine color reagent (Hack Chemical Company, Ames, Iowa). Dissolve $150 \mathrm{mg}$ of ferrozine in $10 \mathrm{ml}$ of iron-free distilled $\mathrm{H}_{2} \mathrm{O}$.

4. Terosite color reagent (Scientific Products, Detroit, Mich.). Prepare a sulfonated solution from $200 \mathrm{mg} / 10 \mathrm{ml}$ of terosite as previously described for serum iron $(13,14)$.

5. Acetate - ascorbic acid buffer (J. T. Baker Chemical Co., Phillipsburg, N. J.). Dissolve $41 \mathrm{~g}$ of sodium acetate in distilled $\mathrm{H}_{2} \mathrm{O}$, add $30.3 \mathrm{ml}$ of glacial acetic acid and $15 \mathrm{~g}$ of ascorbic acid and make the solution up to a final volume of $500 \mathrm{ml}$.

\section{Procedure}

Ferrozine

Pipet $1.0 \mathrm{ml}$ of clorox solution and $1.0 \mathrm{ml}$ of Brij-35 solution into a test tube, then add $20 \mu \mathrm{l}$ of well mixed oxalated blood. After $5 \mathrm{~min}$ add $3.0 \mathrm{ml}$ of buffered reducing agent and $1.0 \mathrm{ml}$ of ferrozine color reagent. Wait $20 \mathrm{~min}$ before determining the absorbance of the final color at $562 \mathrm{~nm}$ against a reagent blank.

\section{Terosite sulfonate}

The procedure is similar except that the sample size is smaller so that terosite sulfonate can be conserved. The identical color reagent is used in our laboratories for the determination of serum iron $(13,14)$. The procedure for hemoglobin iron is as follows: Pipet $0.5 \mathrm{ml}$ of clorox and $0.5 \mathrm{ml}$ of Brij-35 solution into each of two $16 \times 100 \mathrm{~mm}$ tubes. Add $10 \mu \mathrm{l}$ of well mixed oxalated blood into one of the two tubes and nothing to the other which

1) In partial fulfillment of the Ph. D. in Biochemistry.

2) Supported in part by the Detroit General Hospital Research Corporation. 


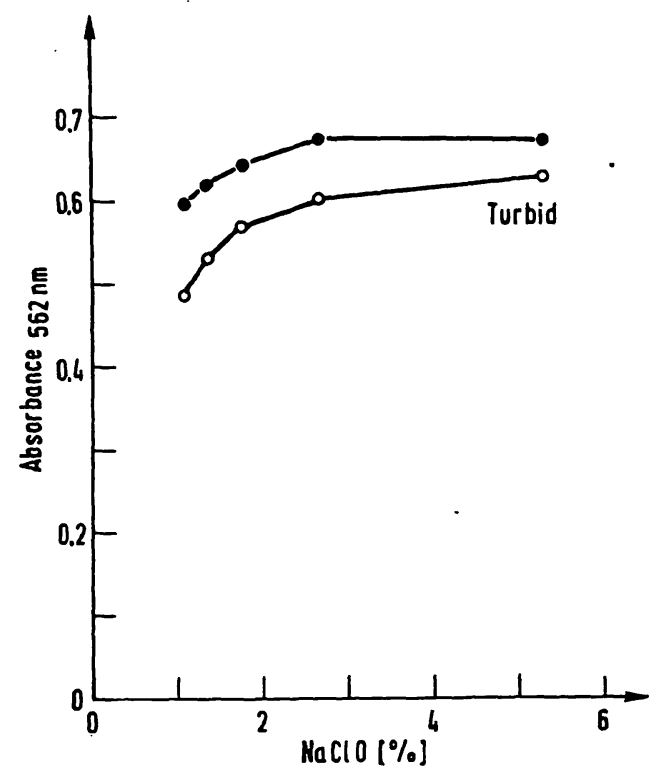

Fig. 1

The effect of varying the clorox concentration is shown for two different time periods: $15 \mathrm{~min} O-O$ and $45 \mathrm{~min}-0-0$. Turbidity appears when the solution of clorox is too concentrated

is to be used as the reagent blank. Mix well and allow them to stand for $5 \mathrm{~min}$. Add $3.0 \mathrm{ml}$ of buffered ascorbic acid to each tube followed by 0.5 mil of terosite solution, wait 20 min and then read the final color at $583 \mathrm{~nm}$ against the reagent blank.

\section{Results and Discussion}

The graphic results to be described concern the reaction characteristics obtained using the more readily available iron ligand, ferrozine. The same results were obtained using terosite sulfonate but because it would be repetitive to include each, the one reagent was used as the example for both.

\section{Effect of clorox concentration}

Figure 1 describes the graphs obtained when the concentration of clorox was varied and the time of incubation with blood was also lengthened. The plateau of absorbance with concentration was reached at half strength for the commercial solution. However, at either $15 \mathrm{~min}$ or $45 \mathrm{~min}$ both solutions became turbid when full strength clorox was used. Three drops of full strength detergent were added in all cases. Since $15-20 \mathrm{~min}$ was adequate to liberate iron from hemoglobin by use of $50 \%$ commercial clorox solution as indicated at the plateau shown, this condition was determined to be optimal.

\section{Standardization}

Figure 2 shows the sensitive spectra of the different concentrations of iron with 3-(2-pyridyl)-5,6-bis(4phenylsulfonic acid)-1,2,4-triazine under the described conditions. The time required to reach full color formation as shown at the right in the same figure was quite short and almost instantaneous. Therefore, the twenty minutes determined as optimum in the next figure represents a plateau characteristic for the sample which is different from that of the standard.

\section{Time for iron release from bemoglobin}

Several blood samples were tested using the described reagents and varying the time necessary to obtain a plateau point at which the release of iron was complete and the subsequent reaction with ligand ensured. The results of this study are graphed in Figure 3. Here a plateau is reached in approximately $15 \mathrm{~min}$ at room temperature. Examination of the highest concentration indicates that there is some tendency to increase this time period as the hemoglobin concentration of blood increases because the $15 \mathrm{~min}$ absorbance reading yields approximately $99 \%$ of the total value in this instance. It has been pointed out (5) that the release of iron is virtually complete after $3 \mathrm{~min}$ of clorox treatment and this study fairly well confirms this fact. However, in order to ensure quantitative reaction, either a longer time in the color development step is necessary or a more prolonged treatment with clorox is required. Since standardization is not a large volume routine process, this latter time period can be increased to $20 \mathrm{~min}$ as described.
Fig. 2

Spectra for different concentrations of - calibration standards are seen at the left. Time of full color formation for pure iron standards in seen at the right
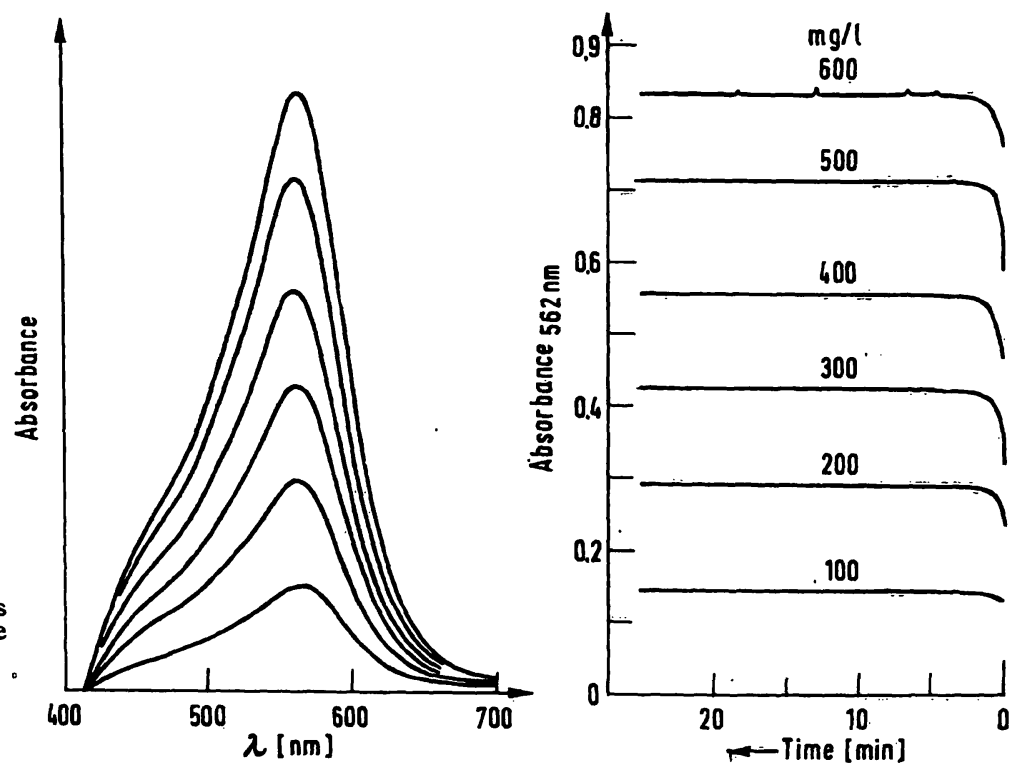


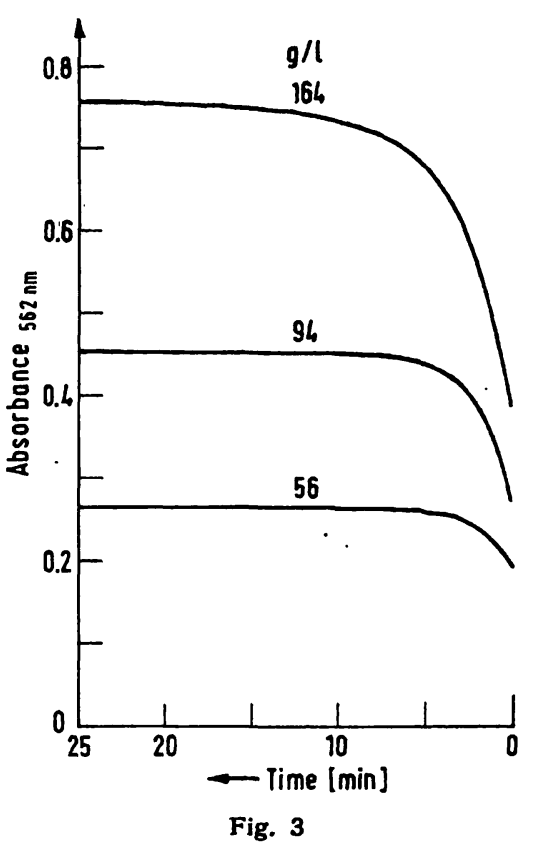

Rate of color formation is shown for several concentrations of hemoglobin in grams per liter of blood

\section{Effect of surface active agent}

Originally 2-3 drops of concentrated Brij-35 solution were added to the $50 \%$ clorox reagent to effect solution of any particulate matter tending to precipitate out when blood was added to this mixture. When a definite concentration of Brij-35 was tried such as $20 \mathrm{ml}$ plus $100 \mathrm{ml}$ of $\mathrm{H}_{2} \mathrm{O}$, and this solution used to prepare $50 \%$ clorox, precipitation did not occur with any bloods tested. When dilutions of the stock Brij-35 solution were made ranging from $1 / 1000$ to as low as $1 / 10,000$, and these then used to dilute the clorox solution it was found that turbidities occurred with certain bloods tested beginning at the $1 / 1000$ dilution. However, these turbidities disappeared after standing for several minutes when concentrations as low as 1/2000 dilution were tested, and the time period before clarification occurred increased as the Brij- 35 concentration was further decreased. Therefore, a $20 \%$ solution of $25 \%$ Brij- 35 was used to prepare the $50 \%$ clorox solution since this represented an excess which ensured clarification and did not cause any interference in the color reaction for iron.

\section{Cyanmetbemoglobin comparative study}

A number of blood samples were carried through the described procedure using the two iron ligands. The results obtained from the iron concentrations found were converted to hemoglobin values using the most recent factor (5). These values were compared to those found when a standard cyanmethemoglobin procedure was used to determine the hemoglobin content of the same blood samples. The comparative findings are shown in Tables 1 and 2 for terosite sulfonate and ferrozine respectively. The comparisons indicate that all three procedures achieve similar results.
Tab. 1

Comparison of hemoglobin values obtained by cyanmethemoglobin determinations and terosite iron determinations

All values are in $\mathrm{g} / \mathrm{l}$. The values can be converted to $\mathrm{mmol} / \mathrm{l}$ by use of the molecular weight of hemoglobin, 64,500

\begin{tabular}{cccc}
\hline $\begin{array}{c}\text { Cyanmethemo- } \\
\text { globin } \\
\text { Hemoglobin }[\mathrm{g} / \mathrm{l}]\end{array}$ & $\begin{array}{c}\text { Terosite } \\
\text { globin } \\
\text { Hemoglobin }[\mathrm{g} / \mathrm{l}]\end{array}$ \\
\hline 112 & 112 & 113 & 113 \\
146 & 142 & 155 & 151 \\
138 & 134 & 113 & 110 \\
115 & 115 & 125 & 126 \\
120 & 120 & 140 & 140 \\
85 & 80 & 121 & 118 \\
89 & 93 & 114 & 113 \\
123 & 126 & 123 & 121 \\
81 & 85 & 97 & 98 \\
98 & 94 & 146 & 147 \\
113 & 110 & 112 & 110 \\
147 & 146 & 143 & 140 \\
137 & 140 & & \\
\hline
\end{tabular}

Tab. 2

Comparison of hemoglobin values obtained by cyanmethamoglobin determinations and ferrozine iron determinations

All values are in $\mathrm{g} / \mathrm{l}$. The values can be converted to $\mathrm{mmol} / \mathrm{l}$ by use of the molecular weight of hemoglobin, 64,500

\begin{tabular}{cccc}
\hline $\begin{array}{c}\text { Cyanmethemo- } \\
\text { globin } \\
\text { Hemoglobin }[\mathrm{g} / \mathrm{l}]\end{array}$ & Ferrozine & $\begin{array}{c}\text { Cyanmethemo- } \\
\text { globin } \\
\text { Hemoglobin }[\mathrm{g} / \mathrm{l}]\end{array}$ \\
\hline 128 & 127 & 115 & Ferrozine \\
70 & 70 & 117 & 116 \\
105 & 106 & 136 & 136 \\
101 & 106 & 116 & 120 \\
100 & 102 & 127 & 134 \\
127 & 126 & 128 & 132 \\
82 & 81 & 90 & 90 \\
84 & 87 & 89 & 91 \\
140 & 144 & 101 & 104 \\
144 & 146 & 142 & 142 \\
156 & 155 & 125 & 126 \\
116 & 118 & 127 & 134 \\
\hline
\end{tabular}

Obviously, if the two iron procedures are to be used as standardization procedures, comparing them to a procedure for which they are to be used as calibration devices may be insufficient proof of accuracy. However, since it has already been proven that either ligand when properly used is accurate and sensitive for the determination of iron $(13,14)$, only ancillary proof of iron release along with the cyanmethemoglobin comparison seems necessary at this stage to show usefulness for the purpose of standardization. An example of the ability to determine iron in an absolute way was derived from the following experiment. Thirty iron solutions of known concentration which contained a scattering of iron values ranging from 96 to $333 \mu \mathrm{g}$ of iron per ml of water were treated as described under both procedures. The results found in this recovery study were used to calculate the standard deviation as a measure of the precision of the spectrophotometry and it turned out to be $\pm 2.7 \mu \mathrm{g} / \mathrm{ml}$. 


\section{References}

1. Cameron, B. F. (1970), Anal. Biochem. 35, 515-517. 2. Wrlliams, L. A. \& Zak, B. (1957), Amer. J. Clin. Pathol. 28 , 195-199. - 3. Martinek, R. G. (1970), J. Amer. Med. Technol. 32, 37-63. - 4. Wong, S. Y. (1923), J. Biol. Chem. 55, 421-425. 5. Klein, B., Weber, B. K., Lucas, L., Foreman, J. A. \& Searcy, R. L. (1969), Clin. Chim. Acta 26, 77-84. - 6. Baginski, E. S. FoA, P. P., Suchocka, S. M. \& ZAK, B. (1969), Microchem. J. 14, 293-297. - 7. Street, H. V. J. (1961), J. Forensic Med. 8, 47-49. - 8. Dickenman, R. C., CRafts, B. \& ZAK, B. (1954), Arch. Biochem. Biophys. 53, 381-386. - 9. RicE, E. W. (1968), J. Lab. Clin. Med. 71, 319-323. - 10. WinsoR, H. W. (1937),
Iñd. Eng. Chem., Anal. Ed. 9, 453-455. - 11. StọokEx, L. I. (1970), Anal. Chem. 42, 779-781. - 12. Schrlt, A. A. \& TAYLOR, P. J. (1970), Anal. Chem. 42, 220-224. - 13. ZAK, B., BAgrNski, E. S., Epstein, E. \& Werner, L. M. (1971), Clin. Toxicol. 4, 621-629. - 14. ZAK, B., BAgINSKr, E. S., Epstein, E. \& WeINer, L. M. (1971), Annals Clin. Lab. Sci. 1, 14-23. - 15. Thomas, J. D. R. (1970), Biochem. Med. 3, 311-320. - 16. Dawes, R. L. F. \& Park, C. (1970), J. Med. Lab. Technol. 27, 55-57. - 17. Connerty, H. V. \& Brigó's, A. R. (1962), Clin. Chem. 8, 151-157.
Prof. Dr. B. Zak

540 East Canfield Are. Detroit/Michigan 48201 USA 